\title{
Cirolana songkhla, a new species of brackish-water cirolanid isopod (Crustacea, Isopoda, Cirolanidae) from the lower Gulf of Thailand
}

\author{
Eknarin Rodcharoen ${ }^{1, \dagger}$, Niel L. Bruce ${ }^{2, \ddagger}$, Pornsilp Pholpunthin ${ }^{1, \S}$
}

I Department of Biology, Faculty of Science, Prince of Songkla University, Hat Yai, Songkhla, Thailand 90112 2 Museum of Tropical Queensland, Queensland Museum and School of Marine and Tropical Biology, James Cook University; 70-102 Flinders Street, Townsville, Australia 4810; Department of Zoology, University of Johannesburg, South Africa

† http://zoobank.org/8908BB63-AC78-4A41-A9A5-018DE4FF22AA

¥ http://zoobank.org/9DA13F3D-AB3A-43E0-BF49-A71EBB8612D7

§ http://zoobank.org/52AAF3DE-00F0-47FC-90F0-8484B6F4F411

Corresponding author: Eknarin Rodcharoen (eknarin_r@yahoo.com)

Academic editor: P. Araujo | Received 5 November 2013 | Accepted 28 December 2013 | Published 30 January 2014

http://zoobank.org/029F5208-22F7-41A6-8881-1AFB9FEA6AE6

Citation: Rodcharoen E, Bruce NL, Pholpunthin P (2014) Cirolana songkhla, a new species of brackish-water cirolanid isopod (Crustacea, Isopoda, Cirolanidae) from the lower Gulf of Thailand. ZooKeys 375: 1-14. doi: 10.3897/zooke ys. 375.6573

\begin{abstract}
Cirolana songkhla sp. n. was collected from brackish-water habitats including lagoons and estuaries in the coastal zone of the lower Gulf of Thailand. C. songkhla sp. n. is described and fully illustrated; C. songkbla sp. n. can be recognized by the presence of abundant chromatophores dorsally, lack of ornamentation on the posterior pereonites, pleonites and pleotelson, the number of robust setae on the uropodal and pleotelson margins (uropod exopod lateral margin with 12-14 RS, mesial margin with 5-8 RS; endopod lateral margin with 8-10 RS, mesial margin with 11-13 RS; pleotelson with 12-15 RS) and lack of setae on the endopods of pleopods 3-5. A dichotomous key of brackish Cirolana species in Thailand is given.
\end{abstract}

\section{Keywords}

Isopoda, Cirolanidae, Cirolana, new species, brackish water, Thailand

Copyright Eknarin Rodcharoen et al. This is an open access article distributed under the terms of the Creative Commons Attribution International License (CC BY 4.0), which permits unrestricted use, distribution, and reproduction in any medium, provided the original author and source are credited. 


\section{Introduction}

The family Cirolanidae has received little attention in Thailand and South-East Asia in general, with only 13 species in eight genera known from Thailand. The genus Cirolana Leach, 1818, the largest genus in the family with 129 species (Bruce and Schotte 2013) is equally poorly known in the region. Suvatti (1967) listed the known species from Thailand, while Kensley (2001) listed the species known to date from the Indian Ocean, including the western coasts of Thailand. Recently, Bruce and Olesen (2002) have reported four marine cirolanid species from Andaman Sea including two new species of Cirolana. All the brackish species of Cirolana have been recorded only from the Gulf of Thailand: C. willeyi Stebbing, 1904 from the Mae Klong River, Samut Songkhram province (Upper Gulf of Thailand) (Suvatti 1967); and C. pleonastica Stebbing, 1900 and C. parva Hansen, 1890 from Songkhla Lake (Lower Gulf of Thailand) (Chilton 1924, 1926). Chilton's (1924, 1926) records are both now regarded as misidentification as Barnard (1935) suggested that the record of C. pleonastica was in fact C. fluviatilis Stebbing, 1902 and Bruce and Bowman (1982) showed that $C$. parva is restricted to the Caribbean and Central American coasts. Although there had been numerous relatively recent advances in the taxonomy of the Cirolanidae (e.g. see Bruce 1986, Brusca et al. 1995, Keable 2006, Moore and Brusca 2003, Riseman and Brusca 2002), knowledge on Thailand's fauna remains minimal.

This present report corrects Chilton's record of C. parva, describes C. songkhla sp. $\mathrm{n}$., and presents a key of the brackish-water species of Cirolana that occur in Thailand.

\section{Materials and Methods}

Specimens were collected by using baited traps from brackish-water habitats including the lagoon and estuary in the lower Gulf of Thailand (Figure 1). Appendages were dissected and drawn under stereo and compound microscopes with a camera lucida. Morphological characters for the description (based on Bruce 2004) were prepared by using DELTA (Descriptive Language for Taxonomy: Dallwitz et al. 1997). The type material of the new species is deposited at Prince of Songkla University Zoological Collection (PSUZC) and Museum of Tropical Queensland (MTQ).

Abbreviations: PMS, plumose marginal setae; RS, robust seta/setae; CPS, circumplumose setae.

\section{Taxonomy}

\section{Genus Cirolana Leach, 1818}

http://species-id.net/wiki/Cirolana

Restricted synonymy. Bruce 1986: 139, Kensley and Schotte 1989: 132, Brusca et al. 1995: 17. 


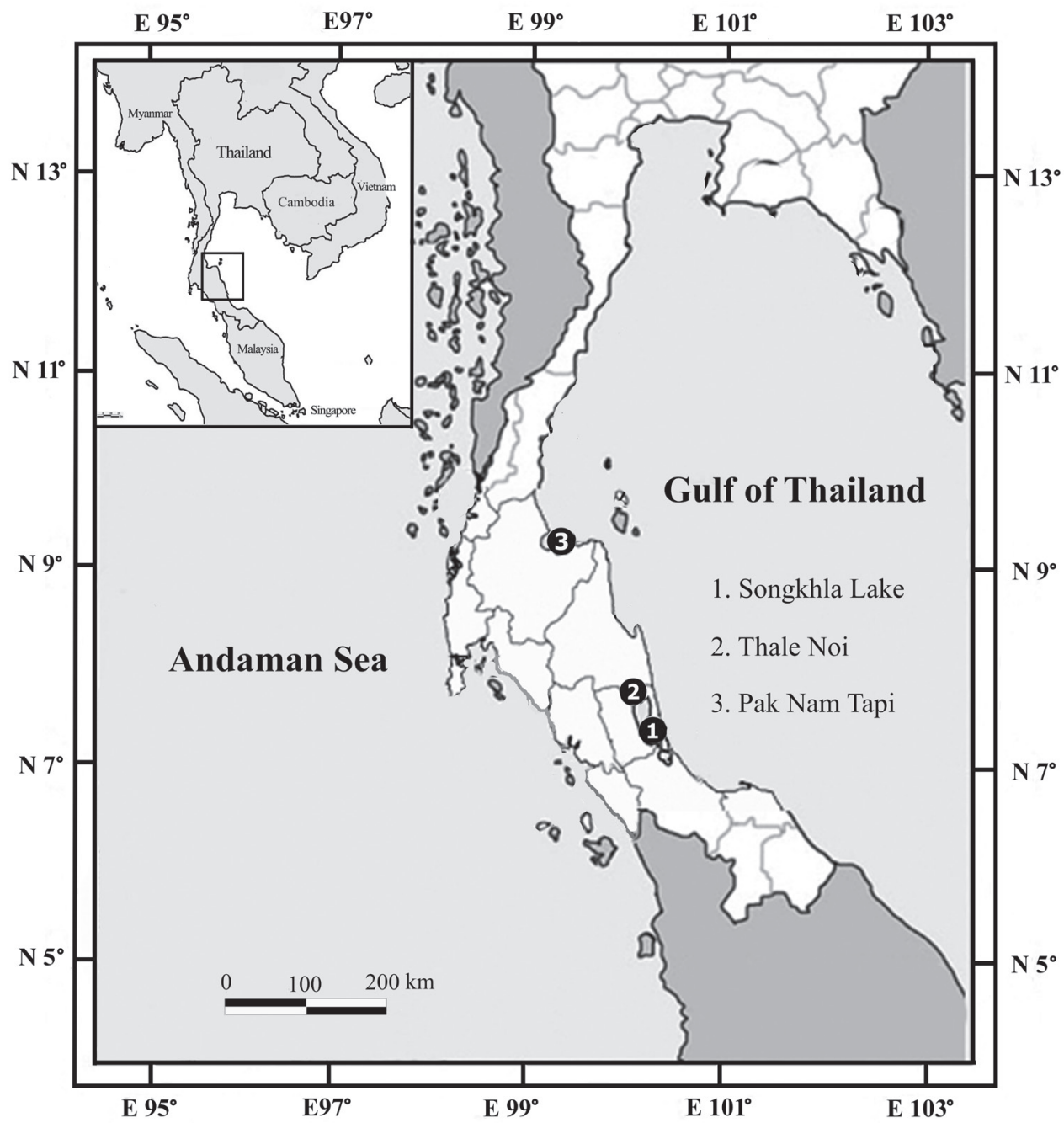

Figure I. Map of sampling sites.

Remarks. Cirolana is the largest genus of the Cirolanidae (Bruce 1981, 1986, Brusca et al. 1995, Keable 2006) with 129 named species (Bruce and Schotte 2013) and many more not yet described. Cirolana occurs from cool-temperate to tropical regions, primarily in marine environments, but also occasionally found in low-salinity habitats, such as mangroves, estuarine reaches of rivers and creeks (Bruce 1986), and also rarely found in freshwater and cave and ground waters (Kensley and Schotte 1989, Botosaneanu and Iliffe 2000). Most low salinity and freshwater species of Cirolana lack setae on the endopods of pleopods 3 and 4, and were formerly placed in the genus Anopsilana Paulian \& Delamare-Debouteville, 1956 (e.g. Bruce 1986; Bruce and Iliffe 
1993), but following Botosaneanu and Iliffe (1997) the genus is now accepted as a junior synonym of Cirolana.

Diagnoses to the genus have been given by Bruce (1986), Brusca et al. (1995) and Kensley and Schotte (1989).

\section{Cirolana songkbla sp. $\mathrm{n}$.}

http://zoobank.org/40967001-288A-433E-8B14-A411034CE8A7

http://species-id.net/wiki/Cirolana_songkhla

Figs 2-6

?Cirolana parva: Chilton 1924: 883, 1926: 180 (misidentification as Cirolana parva Hansen, 1890 in part of freshwater records only; same species as Cirolana songkhla sp. n.).

Material examined. Holotype, $\hat{\jmath}(13.7 \mathrm{~mm})$, middle part of Songkhla Lake, Phattalung province, $07^{\circ} 29.09^{\prime} \mathrm{N}, 100^{\circ} 20.11^{\prime} \mathrm{E}, 23$ October 2011 , gravel bottom and associated with water plants, salinity 4 ppt, coll. E. Rodcharoen (PSUZC-CR0281-01).

Paratypes, $10 \hat{\partial}(13.8,11.2,12.4,10.2,10.3,10.0,13.8,11.8,11.4,10.6 \mathrm{~mm}$ [dissected]), 1 ㅇ (ovig. $8.7 \mathrm{~mm}$ [dissected]), further specimens unmeasured, same data as holotype (PSUZC-CR0281-02; MTQ W34265). 8 ô (11.1, 12.8, 12.2, 13.9, 13.2, 12.4, 12.2, $9.8 \mathrm{~mm}$ [dissected]), 4 + (ovig. 8.6, 8.7 [dissected], 8.8, $9.0 \mathrm{~mm}$ ), further specimens unmeasured, Klong Ban Klang, Thale Noi, Phattalung province, $07^{\circ} 46.44^{\prime} \mathrm{N}, 100^{\circ} 09.27^{\prime} \mathrm{E}, 27$ May 2013 clay bottom, salinity $0.6 \mathrm{ppt}$, coll. E. Rodcharoen (PSUZC-CR0281-03; MTQ W34266).

Additional material. 12 ( (unmeasured), same data as holotype (PSUZCCR0281-04), 38 and 3 + (unmeasured), same data as paratype PSUZC-CR0281-03; MTQ W34266 (PSUZC-CR0281-05; MTQ W34267), 1 adult $\delta$ and 3 juvenile (unmeasured), Pak Nam Tapi (estuary), Surat Thani province, $09^{\circ} 10.31^{\prime} \mathrm{N}, 99^{\circ} 21.36^{\prime} \mathrm{E}$, 30 October 2012 coll. E. Rodcharoen (PSUZC-CR0281-06).

Description of male. Body 3.2 times as long as greatest width, dorsal surfaces smooth, widest at pereonite 5 and pereonite 6 , lateral margins subparallel (Figure 2A). Rostral point (Figure 2C) present, folded ventrally and posteriorly, in contact with frontal lamina (Figure 2D, E). Eye colour dark brown; eyes separated by about $81 \%$ width of head (Figure 2C). Pereonite 1 and coxae 2-3 each with posteroventral angle rounded; coxae 5-7 with entire oblique carina; posterior margins of pereonites 5-7 smooth (Figure 2B). Pleon (Figure 2F) with pleonite 1 largely concealed by pereonite 7; pleonites 3-5 posterior margins smooth; posterolateral angles of pleonite 2 forming acute point, extending posteriorly to anterior of pleonite 4; pleonite 3 with posterolateral margins extending clearly beyond posterior margins of pleonites 4 and 5, narrowly rounded; posterolateral margin of pleonite 4 rounded, clearly extending beyond posterior margin of pleonite 5. Pleotelson (Figure 6E) 1.0 times as long as anterior width, dorsal surface without longitudinal carina; lateral margins convex; margins weakly serrate, posterior margin converging to small distinct caudomedial point, with 12 RS (Figure 6E, F). 

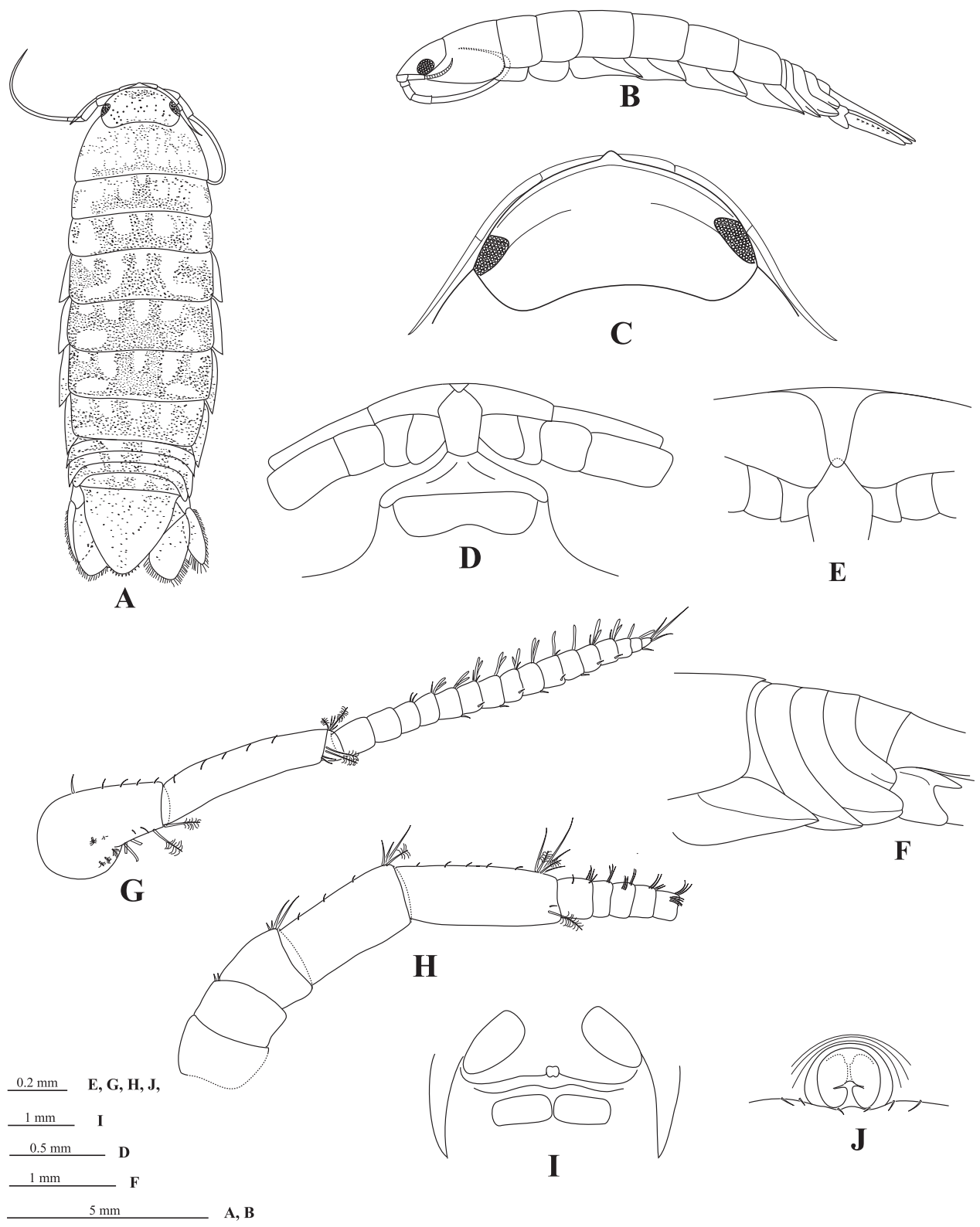

Figure 2. Cirolana songkhla sp. n., male holotype (PSUZC-CR0281-01) (13.7 mm) (A-F), male paratype (PSUZC-CR0281-2) (11.2 mm) (G-H), male paratype (PSUZC-CR0281-2) (13.8 mm) (I-J). A dorsal view B lateral view $\mathbf{C}$ head, dorsal view $\mathbf{D}$ frons $\mathbf{E}$ detail of frontal lamina $\mathbf{F}$ pleon $\mathbf{G}$ antennule $\mathbf{H}$ antennal peduncle $\mathbf{I}$ antero-ventral view of penial opening $\mathbf{J}$ ventral view of penial opening.

Antennule (Figure 2G) peduncle articles 1 and 2 entirely fused; articles 3 and 4 1.3 times as long as combined lengths of articles 1 and 2, article 35.0 times as long as wide; flagellum with 16 articles, extending to middle of pereonite 1. Antenna 
(Figure 2H) peduncle article 41.8 times as long as wide, 2.2 times as long as article 3 , anterodistal angle with 3 short simple setae and 1 plumose seta; article 51.2 times as long as article 4, 2.4 times as long as wide, anterodistal angle with cluster of 4 short simple setae and 2 plumose setae; flagellum with 34 articles, extending to posterior of pereonite 4 .

Frontal lamina (Figure 2D, E) pentagonal, 2.2 times as long as posterior width; 1.6 times as long as greatest width, lateral margins straight, diverging slightly towards anterior, anterior margin acute, with small median point.

Mandible molar process (Figure 3A) anterior margin with 19 flat teeth; with proximal cluster of long simple setae; right mandible spine row composed of 13 spines; palp article 2 with 21 distolateral setae, palp article 3 with 22 biserrate RS (Fig 3B). Maxillule (Figure 3C) mesial lobe with 3 large circumplumose RS; lateral lobe with 13 RS (weakly serrated). Maxilla (Figure 3D) lateral lobe with 4 long setae; middle lobe with 12 long setae; mesial lobe with 4 distal plumose setae and 14 proximal plumose setae. Maxilliped palp (Figure 3E) article 1 mesial margin with 1 slender seta; article 2 mesial margin with 6 slender setae, lateral margin distally with 2 slender setae; article 3 mesial margin with 15 slender setae, lateral margin with 13 slender setae; article 4 mesial margin with 17 slender setae, lateral margin with 9 slender setae; article 5 distal margin with 18 setae, lateral margin with 6 setae; endite (Figure 3F) with 6 long CPS, and 2 coupling setae.

Pereopod 1 (Figure 4A, C) basis 2.3 times as long as greatest width, inferior distal angle with cluster of 2 acute setae; ischium 0.5 times as long as basis, inferior margin with 1 acute seta, inferior distolateral margin with 2 setae (1 molariform RS and 1 acute seta), median distolateral margin with 2 acute setae, superior distal margin with 3 RS; merus inferior margin with 6 molariform RS, (set in rows of 4 and 2), superior distal angle with 3 setae (slender); carpus inferior distal margin with 2 setae (1 RS and 1 acute seta); propodus 2.0 times as long as wide, inferior margin with 2 RS; dactylus (Figure 4B) 0.5 times as long as propodus. Pereopod 2 (Figure 4D) ischium inferior margin with 2 stout, bluntly rounded RS, superior distal margin with 3 RS; merus inferior margin with 10 stout RS, set in one row, superior distal margin with 6 acute RS; carpus inferodistal angle with 3 RS (plus 1 slender seta); propodus 3.5 times as long as wide; dactylus 0.7 times as long as propodus. Pereopod 3 similar to pereopod 2. Pereopod 4 (Figure 4E) intermediate in from between pereopod 3 and pereopod 5. Pereopod 6 (Figure 4F) similar to pereopod 7. Pereopod 7 (Figure 4G) basis 3.0 times as long as greatest width, superior margin weakly convex, inferior margin with 3 palmate setae; ischium 0.8 times as long as basis, inferior margin with 8 RS (set in groups of 3, 3, 1 and 1), superior distal angle with 6 RS (5 simple, 1 biserrate), inferior distal angle with 2 RS; merus 0.5 times as long as ischium, 2.0 times as long as wide, inferior margin with $3 \mathrm{RS}$, superior distal angle with $6 \mathrm{RS}$ (3 simple, 3 biserrate), inferior distal angle with 7 RS; carpus 0.7 times as long as ischium, 2.4 times as long as wide, inferior margin with $6 \mathrm{RS}$ (set in groups of 2 and 4), superior distal angle with 11 RS (4 simple, 7 biserrate), inferior distal angle with 9 RS (6 simple, 3 biserrate); propodus 0.8 times as long as ischium, 5.4 times 

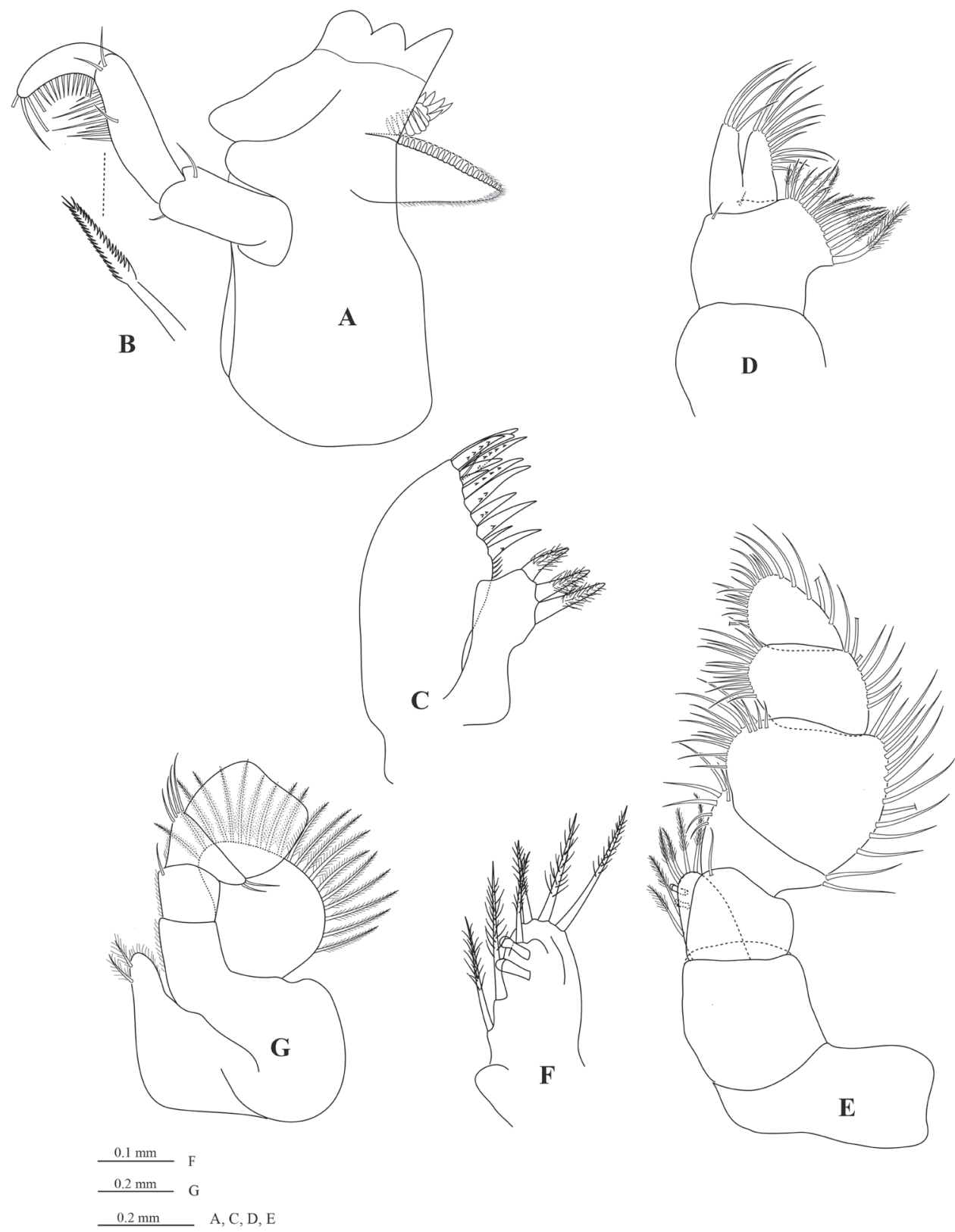

Figure 3. Cirolana songkhla sp. n., male paratype (PSUZC-CR0281-2) (11.2 mm) (A-F), ovigerous female paratype (PSUZC-CR0281-2) $(8.7 \mathrm{~mm})(\mathbf{G})$. A right madible B robust setae $\mathbf{C}$ right maxillule $\mathbf{D}$ right maxilla $\mathbf{E}$ right maxilliped $\mathbf{F}$ maxilliped endite $\mathbf{G}$ left maxiliped, basal articles.

as long as wide, inferior margin with 7 RS (set in groups of 1, 2, 2 and 2), superior distal angle with 3 slender setae and 1 palm seta, inferior distal angle with 2 RS; dactylus 0.3 times as long as propodus. 


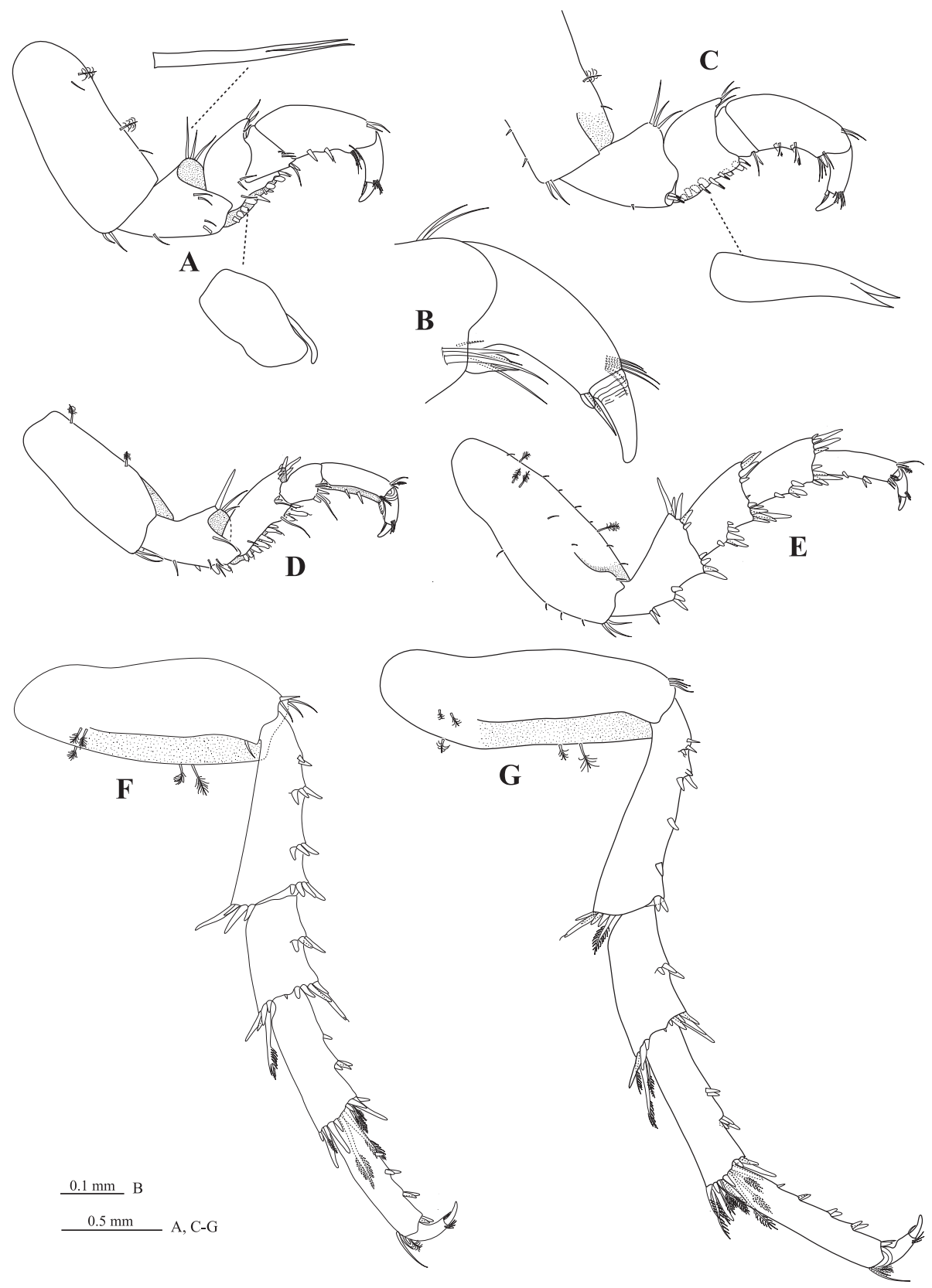

Figure 4. Cirolana songkhla sp. n., male paratype (PSUZC-CR0281-2) (11.2 mm). A pereopod 1 B dactylus of pereopod $1 \mathbf{C}$ mesial view, pereopod 1 D pereopod $2 \mathbf{E}$ pereopod $4 \mathbf{F}$ pereopod $6 \mathbf{G}$ pereopod 7 .

Penes (Figure 2I, J) medially united low papillae.

Pleopod 1 (Figure 5A) exopod 1.3 times as long as wide, lateral margin weakly convex, distally broadly rounded, mesial margin weakly convex, with $\sim 35$ PMS from 
distal one-third; endopod 2.1 times as long as wide, distally broadly rounded, lateral margin sinuate, with -16 PMS on distal margin only; peduncle 1.9 times as wide as long, mesial margin with 4 coupling hooks. Pleopod 2 (Figure 5B) exopod with -52 PMS, endopod with -24 PMS; appendix masculina with parallel margins, 1.0 times as long as endopod, distally notch. Pleopod 3 (Figure 5C) endopod without PMS, exopod with -60 PMS. Pleopod 4 (Figure 5D) endopod without PMS, exopod with -60 PMS. Pleopod 5 (Figure 5E) endopod without PSM, exopod with -54 PMS. Pleopods 2-5 peduncle distolateral margin with prominent acute RS, 3-5 endopods with distomesial serrate scales.

Uropod (Figure 6A) peduncle ventrolateral margin (Figure 6D) with 2 RS, lateral margin with 1 mesial short acute RS, posterior lobe about one-half as long as endopod; rami extending beyond pleotelson, marginal setae in single tiers, apices acute. Endopod (Figure 6A) apically sub-bifid, medial process prominent (Figure 6C); lateral margin weakly convex, with 8 RS, mesial margin strongly convex, with 12 RS. Exopod (Figure 6A) not extending to end of endopod, 3.3 times as long as greatest width, apically subbifid, medial process prominent (Figure 6B); lateral margin weakly convex, with 13 RS; mesial margin weakly convex, with 6 RS.

Female. Similar to male but on average smaller. Antennal flagellum slightly longer, extending to anterior of pereonite 5; maxilliped with lamina vibrans (Figure 3G); brood pouch composed of 5 pairs of oostegites (Figure 6G) arising on sternites 1-5 (as recorded for some other Cirolana species, such as Cirolana (Anopsilana) barnardi (Bruce, 1992) and Cirolana kokoru Bruce, 2004), lateral margin of oostegite 4 with -23 slender setae.

Variation. Pleotelson ( $\mathrm{n}=23$ [18 ${ }^{\mathrm{A}}$ and 5 \% ] ) with 12-15 RS, with $14 \mathrm{RS}(7+7)$ most frequent $(74 \%), 12(4 \%)$ and 15 (4\%) occurring only once. Uropod endopod mesial margin with 11-13 RS, with $12(52 \%)$ and $11(39 \%)$ most frequent, lateral margin with 8-10 RS, with 8 (52\%) and $9(39 \%)$ most frequent; exopod mesial margin with 5-8 RS, with 7 (39\%) and 6 (35\%) most frequent, lateral margin with 12-14, with $13(74 \%)$ most frequent.

Size. Adult males $(\mathrm{n}=19) 9.8-13.9 \mathrm{~mm}$ (mean $11.9 \mathrm{~mm})$; ovigerous females $(\mathrm{n}=5)$ 8.6-9.0 mm (mean $8.8 \mathrm{~mm}$ ).

Remarks. The presence of abundant chromatophores and lack of ornamentation on the posterior pereonites, pleonites and pleotelson excludes $C$. songkhla sp. n. from the Cirolana 'tuberculate-group' (see Bruce 1986). Although C. songkhla sp. n., with smooth dorsal surface, seems to belong to the Cirolana 'parva-group' of Bruce (2004), there are several characters that differ to that group. The body size of $C$. songkhla sp. $\mathrm{n}$. is significantly larger than most tropical 'parva-group' species, most which do not exceed $7 \mathrm{~mm}$. Moreover, the uropods and pleotelson margins are far more heavily armed with robust setae than the 'parva-group'; and the coxae of $C$. songkhla sp. n. are more visible in dorsal view than usually for the 'parva-group'.

C. songkhla sp. $\mathrm{n}$. is characterized by lacking plumose setae on endopods of pleopods 3-5. This character is particularly associated with brackish and freshwater cirolanid species, formerly placed in the genus and then subgenus Anopsilana (Bruce 

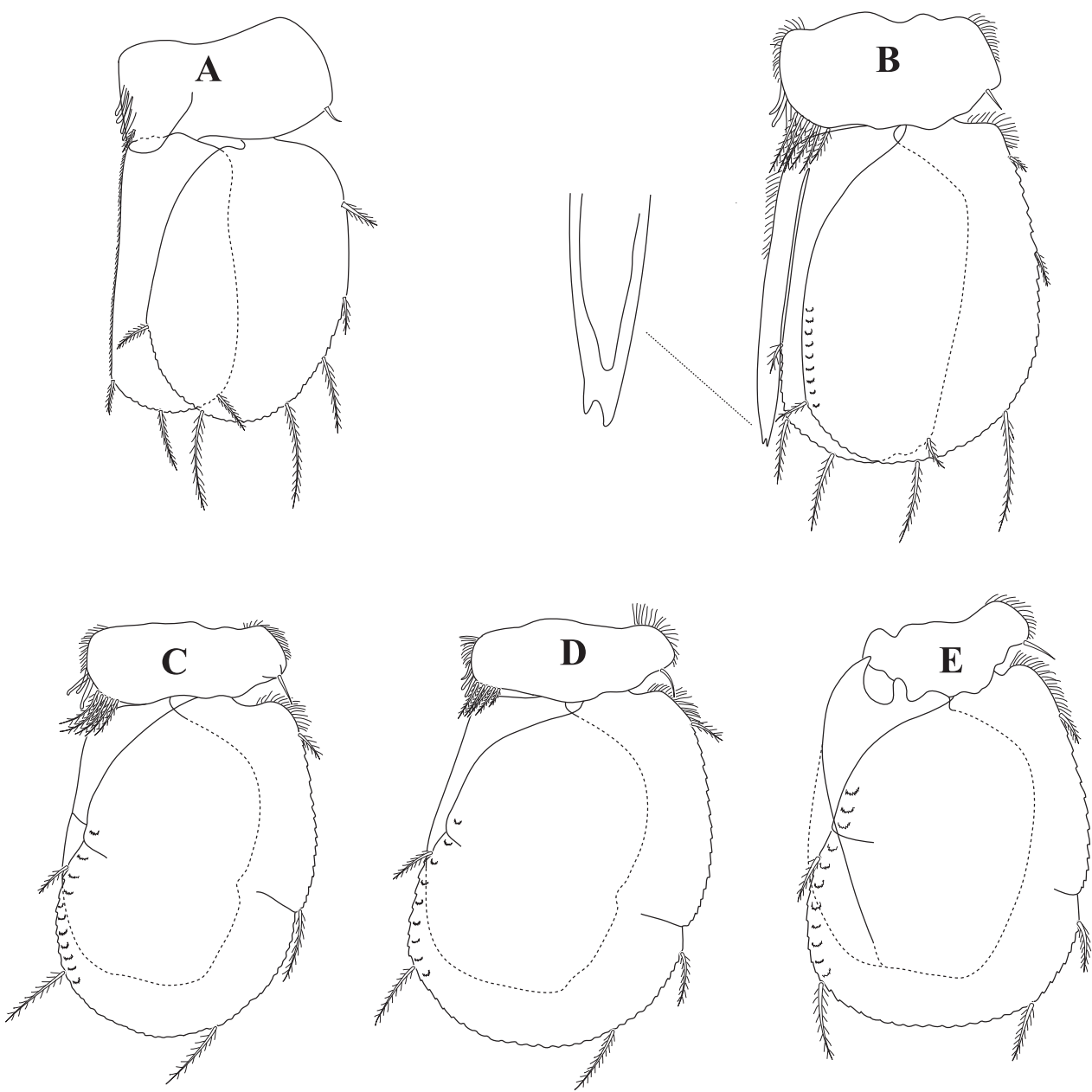

$\underline{0.2 \mathrm{~mm}} \mathrm{~A}-\mathrm{E}$

Figure 5. Cirolana songkhla sp. n., male paratype (PSUZC-CR0281-2) (11.2 mm) A-E pleopods 1-5 respectively.

1981, Botosaneanu and Iliffe 1997). However, C. songkhla sp. n. can be distinguished from the other species of Cirolana (Anopsilana) by having well-developed eyes (absent in freshwater cave species) and smooth dorsal surfaces [nodular and tubercular in species, such as C. fluviatilis Stebbing, 1902 and C. willeyi Stebbing, 1904].

Only Cirolana barnardi (Bruce, 1992) from tropical eastern Australia is similar to $C$. songkhla sp. n. having in common a smooth dorsal surface, rostral point and pentagonal frontal lamina. However, the two species can be clearly distinguished by body size of $C$. songkhla sp. n., which is larger than that of $C$. barnardi (male average at 11.9 VS $3.9 \mathrm{~mm}$, ovigerous female at $8.8 \mathrm{VS} 4.0 \mathrm{~mm}$ ). Furthermore, C. songkhla 


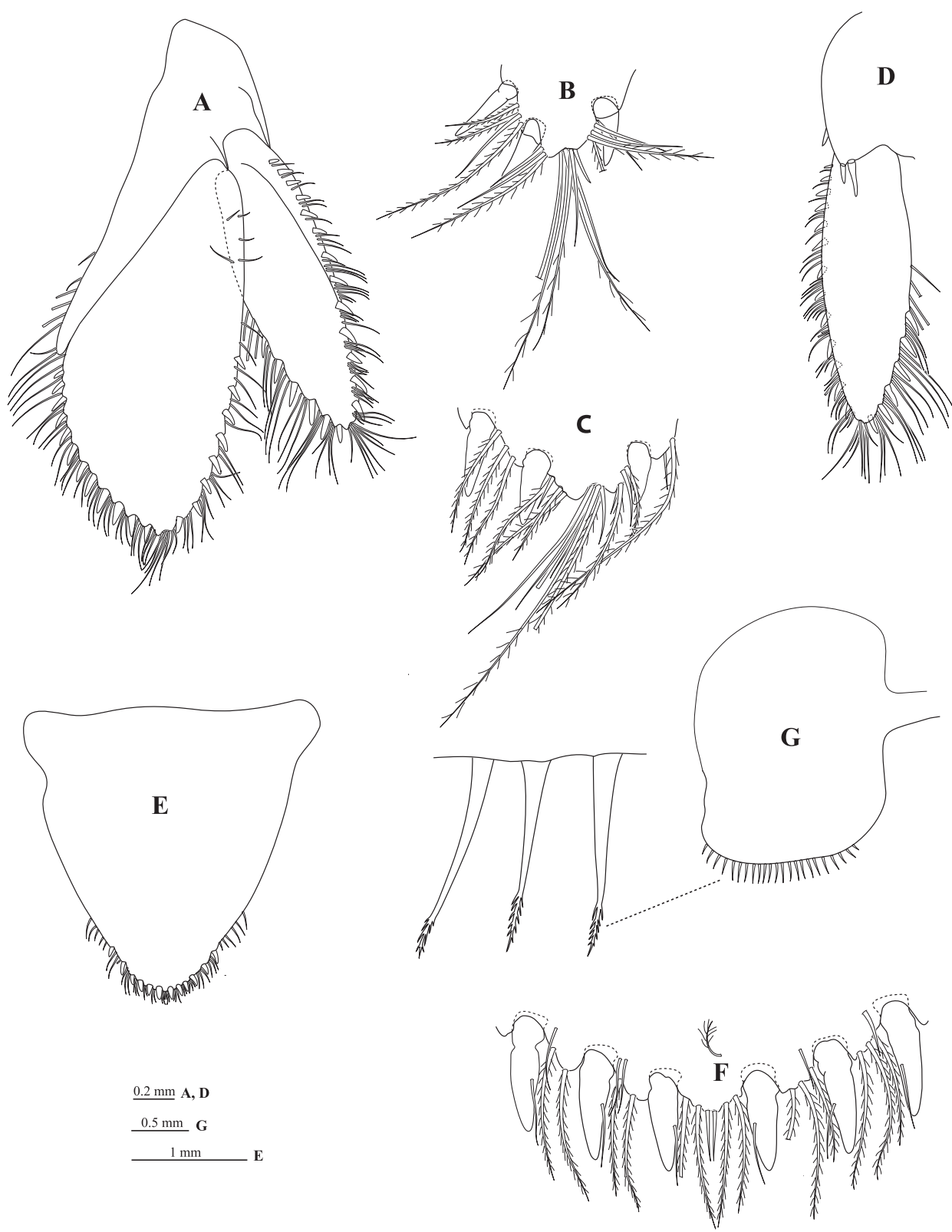

Figure 6. Cirolana songkhla sp. n., male paratype (PSUZC-CR0281-2) (11.2 mm) (A-F), ovigerous female (PSUZC-CR0281-2) (8.7 mm) (G). A uropod B uropod exopod apex $\mathbf{C}$ uropod endopod apex $\mathbf{D}$ uropod exopod $\mathbf{E}$ pleotelson $\mathbf{F}$ detail of pleotelson apex $\mathbf{G}$ oostegite 4.

sp. n. has more numerous robust setae on the uropodal rami and pleotelson margin than C. barnardi; uropod exopod lateral margin with 12-14 RS (VS 7-10), mesial margin with 5-8 RS (VS 5-6); endopod lateral margin with 8-10 RS (VS 3-4), 
mesial margin with 11-13 RS (VS 5-7) and pleotelson, posterior margin converging to small distinct caudomedial point (VS posterior margin subtruncate), with 12-15 RS (VS 7-10).

Cirolana parva Hansen, 1890 has been recorded in freshwater from Thailand by Chilton $(1924,1926)$ from Songkhla Lake and Talé Sap. C. parva is, unequivocally, restricted to marine habitats in Central America and the Caribbean (Bruce and Bowman 1982), with all Indo-Pacific records being misidentifications (see also Bruce 1986, 1995, 2004; Schotte and Kensley 2005). It is probable that Chilton's specimens, misidentified as C. parva, are the same species as C. songkhla sp. n. Chilton (1924) gives a figure (figure 5, but the locality of the specimens is not stated) of the pleotelson and uropods of the Songkhla Lake species, which has a more acute pleotelson apex but is otherwise compatible with the present material and records the size of the Talé Sap specimens as $9 \mathrm{~mm}$, also compatible with the present species. For those reasons, we provisionally include these records from freshwater in the synonymy for C. songkhla sp. n. Chilton (1924) also included several marine localities and some uncertain localities, and these other records are regarded as being of unknown identity.

Etymology. Cirolana songkhla sp. n. is named for the type locality.

\section{Key to brackish species of Cirolana in Thailand}

1 Anterior margin of head without rostral point; frontal lamina anterior margin

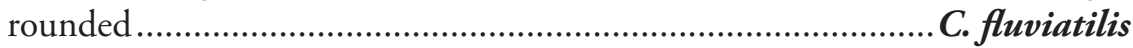

- $\quad$ Anterior margin of head with rostral point, folded ventrally and posteriorly, in contact with frontal lamina; frontal lamina pentagonal...........................2

2 Body dorsal surface without ornamentation; pleotelson lateral margins convex....

C. songkbla sp. $\mathrm{n}$.

- $\quad$ Body dorsal surface with tubercles on pereonites, pleonites and pleotelson; pleotelson lateral margins concave

C. willeyi

\section{Acknowledgements}

The first author would like to thank Miss Bongkot Wichachucherd (Seaweed and Seagrass Research Unit) and Mr. Phuripong Meksuwan (Plankton Research Unit) department of biology, Prince of Songkla University for helping to collect the samples, and we are grateful to department of biology, Prince of Songkla University for the laboratory facilities. This work was financed through Graduated School; the Higher Education Research Promotion and National Research University Project of Thailand, Office of the Higher Education Commission, Prince of Songkla University. 


\section{References}

Barnard KH (1935) Report on some Amphipoda, Isopoda, and Tanaidacea in the collections of the Indian Museum. Records of the Indian Museum 37: 279-319.

Botosaneanu L, Iliffe TM (1997) Four new stygobitic cirolanids (Crustacea: Isopoda) from the Caribbean-with remarks on intergeneric limits in some cirolanids. Bulletin de l'Institut Royale des Sciences Naturelles de Belgique, Biologie 67: 77-94.

Botosaneanu L, Iliffe TM (2000) Two new stygobitic species of Cirolanidae (Isopoda) from deep cenotes in Yucatan. Bulletin de l'Institut Royal des Sciences Naturelles de Belgique, Biologie 70: 149-161.

Bruce NL (1981) Cirolanidae (Crustacea: Isopoda) of Australia: Diagnoses of Cirolana Leach, Metacirolana Nierstrasz, Neocirolana Hale, Anopsilana Paulian \& Debouteville, and three new genera - Natatolana, Politolana and Cartetolana. Australian Journal of Marine and Freshwater Research 32: 945-966. doi: 10.1071/MF9810945

Bruce NL (1986) Cirolanidae (Crustacea: Isopoda) of Australia. Records of the Australian Museum, Supplement 6: 1-239.

Bruce NL (1992) Anopsilana barnardi, a new species of estuarine cirolanid crustacean isopod from tropical eastern Australia. Memoirs of the Queensland Museum 32(1): 1-8.

Bruce NL (1995) Cirolana and related marine isopod crustacean genera (family Cirolanidae) from the coral reefs of Madang, Papua New Guinea. Cahiers de Biologie Marine 35: 375-413.

Bruce NL (2004) New species of the Cirolana "parva-group” (Crustacea: Isopoda: Cirolanidae) from coastal habitats around New Zealand. Species Diversity 9: 47-66.

Bruce NL, Bowman TE (1982) The status of Cirolana parva Hansen, 1890 (Crustacea, Isopoda, Cirolanidae) with notes on its distribution. Proceedings of the Biological Society of Washington 95: 325-333.

Bruce NL, Iliffe TM (1993) Anopsilana conditoria, a new species of anchialine troglobitic cirolanid isopod (Crustacea) from the Philippines. Stygologia 7: 225-230.

Bruce NL, Olesen J (2002) Cirolanid Isopods from The Andaman Sea off Phuket, Thailand, with description of two new species. In: Bruce NL, Berggren M, Bussawarit S (Eds) Proceedings of the International Workshop on the Crustacea in the Andaman Sea, Phuket Marine Biological Center (Thailand), 29 November-20 December 1998. Phuket Marine Biological Center Special Publication, 23, Phuket Marine Biological Center, Phuket, 109-131.

Bruce NL, Schotte M (2013) Cirolanidae. In: Schotte M, Boyko CB, Bruce NL, Poore GCB, Taiti S, Wilson GDF (Eds) World marine, freshwater and terrestrial isopod crustaceans http://www.marinespecies.org/isopoda/aphia.php?p=taxdetails\&id=118273

Brusca RC, Wetzer R, France SC (1995) Cirolanidae (Crustacea: Isopoda: Flabellifera) of the Tropical Eastern Pacific. Proceedings of the San Diego Natural History Museum 30: 1-96. Chilton C (1924) Fauna of the Chilka Lake. Memoirs of the Indian Museum 5(12): 875-895. Chilton C (1926) Zoological results of a tour in the Far East. The Tanaidacea and Isopoda of Talé Sap. Records of the Indian Museum 2: 173-185.

Dallwitz MJ, Paine TA, Zurcher EJ (1997) User's guide to the DELTA system. A general system for processing taxonomic descriptions. CSIRO Division of Entomology, Canberra, 160 pp. 
Hansen HJ (1890) Cirolanidae et familiae nonnulae propinquae Musei Hauniensis. Det Kongelige Danske Videnskabernes Selskab Skrifter, Naturvidenskabelig og Mathematisk 6: 237-426.

Keable SJ (2006) Taxonomic revision of Natatolana (Crustacea: Isopoda: Cirolanidae). Records of the Australian Museum 58: 133-244. doi: 10.3853/j.0067-1975.58.2006.1469

Kensley B (2001) Biogeography of the marine Isopoda of the Indian Ocean, with a check-list of species and records. In: Kensley B, Brusca RC (Eds) Isopod systematics and evolution. Crustacean Issues 13: 205-264.

Kensley B, Schotte M (1989) Guide to the marine isopod crustaceans of the Caribbean. Smithsonian Institution Press, Washington, D. C. and London, 308 pp.

Leach WE (1818) Cymothoadés. In: Cuvier F (Ed) Dictionnaire des sciences naturelles. Paris and Strasbourg 12: 338-354.

Moore W, Brusca RC (2003) A monograph on the isopod genus Colopisthus (Crustacea: Isopoda: Cirolanidae) with the description of a new genus. Journal of Natural History 37: 1329-1399. doi: 10.1080/00222930110108335

Paulian R, Delamare-Deboutteville C (1956) Un cirolanide cavernicole a Madagascar [isopode]. Mémoires de l'Institut Scientifique de Madagascar 11: 86-88.

Riseman SF, Brusca RC (2002) Taxonomy, phylogeny and biogeography of Politolana Bruce, 1981 (Crustacea: Isopoda: Cirolanidae). Zoological Journal of the Linnean Society 134: 57-140. doi: 10.1046/j.1096-3642.2002.00002.x

Schotte M, Kensley B (2005) New species and records of Flabellifera from the Indian Ocean (Crustacea: Peracarida: Isopoda). Journal of Natural History 39(16): 1211-1282. doi: 10.1080/00222930400005757

Stebbing TRR (1900) On Crustacea brought by Dr Willey from the South Seas. In: Willey A (Ed) Zoological results based on material from New Britiain, New Guinea, Loyalty Islands and elsewhere, collected during the years 1895, 1896 and 1897. Cambridge University Press, Cambridge, 605-690, pls 64-74.

Stebbing TRR (1902) South African Crustacea. Part 2. Marine Investigations in South Africa 2: $1-92$.

Stebbing TRR (1904) Marine Crustaceans. XII. Isopoda, with description of a new genus. In: Gardiner JS (Ed) Fauna and Geography of the Maldive and Laccadive Archipelagoes, 699-721.

Suvatti C (1967) Phylum Arthopoda. In: Fauna of Thailand $\left(2^{\text {nd }} E d s\right)$ Applied Scientific Research Corporation of Thailand, Bangkok, 127-179. 